\title{
The conclusion of papers published in the Journal should be supported by an appropriate statistical analysis
}

\author{
Eugene H. Blackstone, MD, ${ }^{\mathrm{a}}$ and Richard D. Weisel, $\mathrm{MD}^{\mathrm{b}}$
}

Papers accepted for publication in the Journal will undergo an extensive scientific and statistical review to ensure that the conclusions are based on an appropriate evaluation. Not all papers require such a review, particularly if the observations do not require comparison with other groups or temporal changes. However, most highly cited papers involve an extensive study plan and a complex analysis. The goal of the statistical review will be to assist the authors to clearly describe their study plan, their analysis, and indicate what valid implications can be made.

The goal of the review process is to ensure that published papers on clinical research have the best study design and the most appropriate analysis that adequately supports the conclusions. All submitted manuscripts will be requested to include a statement about whether complex statistics were employed. If none was employed, then a statistical review may not be necessary. However, if any comparisons were made, then an author or a consultant with expertise and experience with study design and statistical methodology should be identified. Particularly for more complex statistics the collaboration with a statistician may be essential. To submit their paper, authors will complete a form that specifies the name and qualifications of their design and statistical expert who should sign the statement verifying their participation in the paper. Statistical collaborators can be from a variety of backgrounds, but they must have sufficient expertise and experience to assist the authors with a statistical plan for their analysis and reporting of the results. Papers that have complex statistics but do not identify a statistical consultant will not be reviewed and will be returned to the authors.

Statistical analysis for the Journal will be performed by a cadre of individuals with extensive experience in study design and statistical methodology. These individuals will be designated as Deputy Statistical Editors. Their reviews will be evaluated by the Statistical Editor and the other Deputies. The final recommendations will have the support of the group and provide the Associate Editors and the Editor with recommendations for acceptance, rejection, or

From the Heart and Vascular Institute, ${ }^{\mathrm{a}}$ Cleveland Clinic, Cleveland, Ohio; and Division of Cardiovascular Surgery, ${ }^{\mathrm{b}}$ Toronto General Hospital, Research Institute and the University of Toronto, Toronto, Ontario, Canada.

Disclosures: Authors have nothing to disclose with regard to commercial support.

Address for reprints: Richard D. Weisel, MD, 200 Elizabeth St 4N-476, Toronto, On-

tario, Canada M5G 2C4 (E-mail: rweisel@uhnresearch.ca).

J Thorac Cardiovasc Surg 2014;148:2479

$0022-5223 / \$ 36.00$

Copyright (c) 2014 by The American Association for Thoracic Surgery

http://dx.doi.org/10.1016/j.jtcvs.2014.10.114

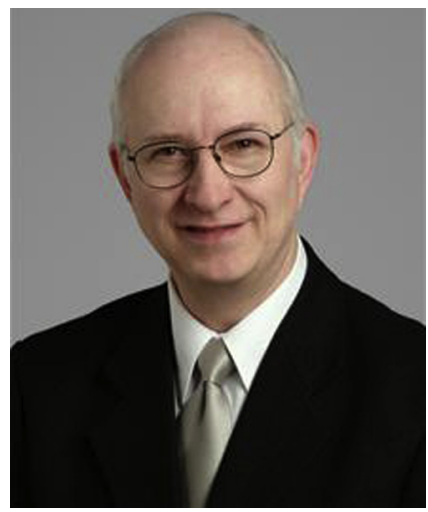

Eugene H. Blackstone

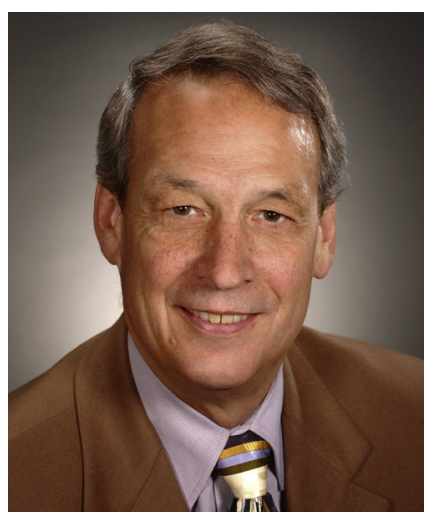

Richard D. Weisel

modification. Revisions will be reviewed by the Deputy Statistical Editors. The Statistical Editor and his Deputies will also will publish information about study and statistical design to assist authors with their manuscript preparation. Updated recommendations will be published periodically in the Journal to keep up with this rapidly changing field and will always be available online at our manuscript submission site. We hope that this initiative will improve the quality of the published papers and raise the level of scholarship in cardiothoracic surgery. 